\title{
Revisiting Global University Rankings
}

\section{R Natarajan ${ }^{1}$, P N Razdan ${ }^{2}$ and Madhu B K ${ }^{3 *}$}

${ }^{1}$ Former Chairman- AICTE and Former Director - IIT Madras, India

${ }^{2}$ Former Vice Chancellor, DPU-Pune and Principal Advisor-Ramaiah Group. Bangalore, India

${ }^{3}$ Assistant Professor, FMC - Ramaiah University of Applied Sciences, Bangalore, India

*Corresponding Author: Madhu B K, Assistant Professor, FMC - Ramaiah University of Applied Sciences, Bangalore, India.

Received: January 10, 2022; Published: January 31, 2022

\section{Summary}

Interest in and popularity of global university rankings have been on the rise worldwide. They have been utilized by the several stakeholders for different types of decision making. There is also general recognition that no ranking system is perfect and there are specific criticisms of each ranking system. One of the most controversial parameters is Perception which THE and QS claim to be the centerpiece of their systems and allot about half of the overall score to it. This aspect is examined here with respect to THE and QS global ranking systems and the national NIRF rankings, by comparing the scores with and without inclusion of the perception scores. It is argued that Perception is entirely subjective and comes in the way of providing a level playing field for all institutions.

\section{Introduction}

There are over two dozen global rankings of universities around the world with distinct parameters and weightings. It is therefore to be expected that there will be differences in the resulting ranking lists. Whenever we see these rankings, we should ask three questions: What are the parameters? What are the weights attached to each parameter? In case of perception scores, who are the stakeholders sampled?

Who publishes University Rankings? Rankings are created and distributed by a variety of entities, including magazines, newspapers, global ranking organizations, such as THE and QS, and national ranking agencies such as NIRF. It is important to keep in mind that the rankings have a number of limitations, and only provide one indication of university performance. Rankings, therefore, should be used as supportive tools, not as a stand-alone measurement. There are several Rankings in vogue, each with its distinct characteristics, and limitations.

Different stakeholders in the education system -student, parent, faculty member, administrator, employer, funding agency, "regulator", employ the ranking lists for different purposes. The rankings have a significant influence on several decision making processes, including, for example, admissions, funding by external sources, awards, employment, etc. It is evident that like "Beauty which lies in the eyes of the beholder", each ranking list appeals to different users differently. There is obviously no perfect ranking system, and therefore there is so much discussion, controversy, and confusion in this area. The presence of considerable subjectivity in decision-making, paucity of reliable and verifiable data, and in some cases, downright lack of integrity, all contribute to distrust in the published rankings.

This Paper focusses on the inclusion and use of Perception scores, and the claims of ranking agencies that they are of utmost importance and are essential. Removing the Perception scores, it is believed, will remove the subjectivity, and furnish a level playing field 
for all institutions.

\section{Alternate Rankings}

It is observed that some universities enjoy a big advantage in the Academic Ranking of World Universities (ARWU), also known as the Shanghai rankings, because of importance given to Fields Medals in Mathematics and Nobel Prizes in the Sciences and Economics. Recently, the Center for World-Class Universities at Shanghai Jiao Tong University has produced an Alternate Ranking from which the Awards and Alumni indicators have been deleted. (Academic Ranking of World Universities, 16 October 2014)

The new rankings continued to show Harvard at the top with Stanford in second place. But there are some significant changes in the rest of the ranking. The top five universities in the world were:

1. Harvard

2. Stanford

3. University of California Berkeley (4th in ARWU)

4. MIT (3rd in ARWU)

5. Caltech (7th in ARWU)

A little further down, Oxford, which has strengths in the arts and humanities, rises from $9^{\text {th }}$ to $6^{\text {th }}$ place, while Cambridge, noted for research in the natural sciences, falls from $5^{\text {th }}$ to $8^{\text {th }}$ place.

Among the universities that suffer disproportionately from the exclusion of the Nobel and Fields awards are Princeton, Moscow Lomonosov State University and University of Paris Sud. Several other continental European universities and Ivy League schools also lose out.

Asian universities and some American state institutions tend to do better when the ranking consists of the remaining four indicators-highly cited researchers, publications in the Science Citation Index and the Social Sciences Citation Index, papers in Nature and Science, and productivity per capita.

The two well-known global university rankings, Quacquarelli Symonds(QS) and Times Higher Education (THE), as well as our NIRF, employ different metrics - parameters and weightings- and hence result in different rankings lists. THE and QS allot approximately half of the points to perception score, while NIRF allots $10 \%$.

\section{The Role of Perception in National and Global Academic Rankings}

Academic Reputation or Prestige is generally defined by Academic Rankings and higher education leaders as the overall impression of excellence or quality represented by a number of factors.

According to research by Garfield, Barker and Graham on measuring "informative effects for universities, the image, or reputation or quality of an institution is regularly more significant than its genuine quality, since it addresses the apparent greatness of the institution ".

Reputation is the officially recognized name or standing for merit, achievement, reliability, etc. To have a reputation for something means to be known or remembered for it; it is the opinion that people have about how good an institution is. If they have a good reputation, people think it is good; It is the Brand that is signified.

\section{Conflicting Perceptions of Ministry of Education on Global Rankings}

One of the conditions for being considered for the recently introduced Institution of Eminence status is that the Institution must figure either in the "Top 50 in the National Institutional Ranking Framework (NIRF) in their category or the Top 500 in internationally 
recognised rankings like the THE or QS University Rankings or SJTU (Shanghai's Jiao Tong University) ARWU rankings".

More recently, the Union Ministry has taken into consideration the criticism and complaint of a few Indian Institutes of Technology, regarding the parameters employed for worldwide university rankings. These IITs have contended that the ranking systems of THE and QS Rankings depend predominantly on perceptions or reputation and accordingly lack objectivity, putting Indian reputed institutions at a disadvantage. "The THE and QS international rankings give 40-50\% weight to academic and employer perceptions" and therefore are subjective in nature. Whereas The NIRF rankings allot just $10 \%$ weight age to this parameter. The IITs boycotted THE world university ranking recently, expressing doubts about the methodology.

\section{The QS Perception Evaluation}

QS claims to take into account the fact that different fields have totally different cultures of publishing -. A citation got for a paper in Philosophy is estimated differently to one got for a paper on Anatomy and Physiology.

QS gives more weight age (40\%) to "academic reputation" than to some other parameters. To determine academic reputation, QS conducts what it calls "the world's biggest survey of academic opinion," with responses from about 70,000 contributors.

QS gives more weight to perceived reputation than THE. It is claimed that the Academic Reputation Index is the centrepiece of the QS World University Rankings."It is a way to deal with global university assessment that QS initiated in 2004 and is the part that invites the most scrutiny".

It is usually determined by surveys, which are criticized to be highly subjective. In combination with Employer Reputation Index, it is the parameter which plays a big role in determining the ranking positions. These two Indices are drawn from two large global surveys - one of academics and the other of employers.

The Surveys have evolved since 2004, but largely follow the same general principles. "Respondents are not asked to comment on the sciences if their expertise is in the arts. Respondents are not asked to comment on Europe if their knowledge is centred on Asia. The study requests that every respondent declare their insight at the beginning, and adapts, dependent on their responses, the list from which respondents are welcome to choose features of only entries from their own region".

The Analysis of the Results is a complex and complicated exercise, and is described in Annexure I. It shows how arbitrary the process is.

"Attracting students is at the core of a university's success";.it is stated. "The actual reputation of an academic institution significantly affects its place in different university rankings, the quantity of applications it draws in, and the subsidizing it gets". "Perceived quality has nearly as much impact on a university's success as actual quality".' Similar to the reputation of a few of the world's leading brands, a university's reputation should be carefully and critically examined".

“The QS Academic Reputation Dataset is considered to enable the institution to further analyse its academic performance and brand perception. It is a benchmarking tool that is exclusively employed for the top performing institutions of the QS World University Rankings". The data collected in the QS Global Academic Survey feeds into the Academic Reputation indicator (40\% weighting in the QS World University Rankings), and therefore, this service is a useful tool to help a university's reputational strategy.

Each report includes all the academics' responses nominating the institution and/or the selected peers, broken down by respondent and institution profiles. This encompasses responses from 5 continents across 140 countries with over 40 disciplines covered.

“The QS Global Employer Survey has seen a significant increase in response, from 17,000 in 2011 to over 50,000 for the 2021 edition of the rankings. Growth has been seen worldwide but especially in Latin America, Russia, India, and China". "Responses are closely scrutinized and weighted to eliminate biases. In order to ensure the stability of the sample, QS combines responses from the last five

Citation: Madhu B K., et al. "Revisiting Global University Rankings". Medicon Engineering Themes 2.2 (2022): 30-37. 
years". Already, questions have been raised with regard to how a few universities have recruited individuals to vote in the QS survey in a manner some say makes the study biased.

Inside Higher $E d$ has discovered that it is as yet feasible for universities to designate individuals to take an interest in the academic survey, even though they are not qualified to offer reliable opinions.

People who are not affiliated with a university and who do not use an email address with the .edu suffix or another sign that may indicate that they are academics, sent to Inside Higher Ed a notification from a university that they were being designated to vote. Furthermore, not long after they got that notification (from a university with which they have no association), the official greeting from QS showed up:

"You're welcome to make your perspectives heard by participating in the QS Global Academic Survey 2018. This survey, sent to leading academics situated in more than 100 nations all over the world, will have a major part and influence in the following version of the QS World University Rankings, the most generally cited worldwide university rankings and a device used widely by students all over the world ," said the greeting, with a connection to the voting framework.

Allowing colleges to designate individuals to vote, the QS approach, varies from the framework used by Times Higher Education, which does an invitation/greetings-only survey that universities being ranked cannot seek to impact.

"We do some fundamental checking and guarantee that the list appears to be legit. The greater part of our screening happens once we get the responses, when we have undeniably additional verifying strategies to distinguish the nature of respondent," a representative for QS said.

\section{Comparison of QS and THE Perception Rankings}

At the outset, it is pertinent to point out that both THE and QS use data from Scopus.

Times Higher Education (THE) published its 2017 reputation rankings which included 100 universities. These are based on a survey distributed between January and March of that year, and included, after standardisation, in the next year's World University Rankings. In the next world rankings, the reputation survey has been divided into two metrics in the research and teaching indicator groups, with a combined weighting of 33 percent. The survey asked about research and postgraduate teaching, but since the correlation between these two questions is very high there is effectively only one indicator.

The QS world rankings released recently included scores derived from two surveys, one of academics with a $40 \%$ weighting and the other of employers with 10\%weighting. The academic survey was concerned only with research.

The methodology of the THE survey is relatively simple. The respondents are drawn from the database of researchers with publications in Scopus-indexed journals, in other words, those who get to be listed as corresponding author. THE claims that this makes them experienced senior researchers although in many parts of the world, being a member or leader of a research team often has more to do with politics than academic merit.

In contrast, the QS methodology has changed quite a lot over the last few years. It began with scouring the mailing lists of World Scientific, a Singapore based academic publisher with links to Imperial College London, then adding various other channels including lists supplied by institutions and sign-up facilities for potential respondents. The result is a survey that appears more inclusive than THE's with more respondents from outside the elite institutions, but one whose validity may be rather suspect.

The THE ranking found that there were six super-brand universities that stood out from everyone else, viz., Harvard, MIT, Stanford, Cambridge, Oxford, and Berkeley. There was a big gap between Berkeley and number seven, Princeton, and then the long smooth slope continued.

Citation: Madhu B K., et al. “Revisiting Global University Rankings". Medicon Engineering Themes 2.2 (2022): 30-37. 
After that, the ranking was dominated by English- speaking universities, with the USA contributing 42, the UK 10, Canada 3, and Australia 3. East Asia and the Chinese diaspora (Hong Kong, Taiwan, and Singapore) were fairly well represented, while South and Central Asia, the Middle East and Africa were absent.

The QS reputation indicator has the same universities in the top six but, not in quite the same order: Cambridge, fourth in THE, is second in the QS indicator. After that it starts looking very different. At number seven is the University of Tokyo, which THE puts in 11th place for academic reputation. Other Asian universities do much better in the QS indicator. The National University of Singapore is 11 th $\left(27^{\text {th }}\right.$ in THE) Nanyang Technological University Singapore is 50th (THE 81-90 band), Peking University is 14th (THE 17th), Chulalongkorn University Thailand is 99th (not in the THE top 100).

It is noticeable that Latin American universities such as the University of Sao Paulo, the University of Buenos Aires and the Pontifical Catholic University of Chile, get a higher placing in the QS indicator than they do in the THE ranking, as do some Southern European universities such as Barcelona, Sapienza and Bologna.

\section{The Criticism from our IITs}

Recently, some of the leading Indian Institutes of Technology (IITs), four of which are on the list of IoEs, announced that they would be boycotting the THE rankings. It is not clear whether this means that there is now a split within the higher education sector in India or whether the IITs are rethinking their opposition to the rankings. It is suggested that the Indian government and others would be wise to take note of the analysis and criticism that is available before committing themselves to using rankings for the assessment of research or higher education.

\section{National Institutional Ranking Framework (NIRF)}

The National Institutional Ranking Framework (NIRF) was launched by MHRD on 29th September 2015 and is announced annually. This framework outlines a methodology to rank institutions across the country. "The methodology draws from the overall recommendations arrived at by a Core Committee set up by MHRD, to identify the broad parameters for ranking various universities and institutions in the country. The parameters include "Teaching, Learning and Resources," "Research and Professional Practice," "Graduation Outcomes," "Outreach and Inclusivity," and "Perception”.

In the earlier versions of NIRF, Perception was treated more comprehensively. The Parameter 5 Perception was decomposed into four components: Peer Perception: Employers and Research Investors (PREMP); Peer Perception: Academics (PRACD); Public Perception (PRPUB); and Competitiveness (PRCMP), each with a weighting of 25 marks.

PREMP is determined through a survey of Institution heads, experts from reputed organizations, officials of funding agencies in government, private sector NGOs, and so on.

PRACD is determined through a survey conducted over a large category of academics to ascertain their preference for graduates of different institutions. PRACD would be based on an on-line survey carried out in a time-bound fashion.

PRPUB is based on data collected online from the public, in response to advertisements. It would ascertain preferences of general public for choosing institutions for their wards and friends.

For universities in the PR parameter, 70\% weight is given to Peer Perception and 30\% to Accreditation.

\section{Present Work}

In the present work, the recent THE, QS -Global, QS- Asia and NIRF rankings are recalculated without inclusion of Perception scores, and compared with scores including Perception scores. Given below are the important results in the three global rankings and the

Citation: Madhu B K., et al. “Revisiting Global University Rankings". Medicon Engineering Themes 2.2 (2022): 30-37. 
national rankings.

\section{Times Ranking}

1. Out of 100 rankings, it is found that in case of 33 universities there is NO change in the ranking, if scores of Perception/ Reputation are taken into consideration or not. Out of these 33 universities, only 13 universities are in the rank band of 1-20.

2. In the case of 56 institutions, the variation in ranks is in the range of 1 to 5 , while in the case of 10 universities the variation is in the range of 6 to 10 .

3. For one university (Kyoto University), the ranking goes down by 15 positions.

4. It may be noted that no Indian University has been ranked in the range of 1-100 in the 2021 Ranking Survey.

\section{QS -World}

1. Out of 100 rankings, it is found that only in the case of 4 universities there is NO change in rankings, if scores of Perception/ Reputation are taken into consideration or not; this includes the $1^{\text {st }}$ and $100^{\text {th }}$ rankings.

2. In the case of 24 institutions the variation in ranks is between 1 to 5 whether scores of Perception/ Reputation are taken into consideration or not. In the case of 13 universities, the variation is in the range of 6 to 10 .

3. The variation is again significant in the higher rankings; and there are 27 universities whose rankings have changed between 11-20, while the case of 22 universities the rankings have varied from 21 to 40 .

4. In the case of 10 universities the rankings have changed by 41 to 73 positions. Out of these, in the case of one university the ranking has decreased by 43 positions, while in the case of 7 universities, the rankings have improved; in one case, the ranking has improved by 73 positions.

\section{QS -Asia Ranking}

1. Out of 100 rankings, it is found that in only in the case of 2 universities there is NO change in ranking, if scores of Perception/ Reputation are taken into consideration or not; both these universities are in the ranking range of 4-8.

2. In the case of 30 institutions, the variation in ranks is between 1 to 5 if scores of Perception/ Reputations are taken into consideration or not; while in case of 14 universities, the variation is in the range of 6 to 10 .

3. The variation is again significant in the higher rankings. There are 25 universities whose rankings have changed between $11-$ 20 , while in the case of 21 universities the rankings have changed from 21 to 40.

4. In the case of 8 universities, the rankings have changed by 41 to 62 positions.

5. It is seen that for 6 Institutions which are placed in the first 100 rankings (which include 4 - IIT's, IISc \& JNU) the rankings have decreased if Reputation score is not taken into consideration. In the case of IIT-D, the ranking has decreased by 38 positions, while in the case of IISc, the ranking has decreased by 11 positions. In the case of JNU, the ranking has improved by 2 positions.

\section{NIRF Ranking}

1. Out of 100 rankings, it is found that in case of 22 universities, there is NO change in ranking whether scores of Perception/ Reputation are taken into consideration or not (out of which, 19 universities are in the range of 1-20).

2. In the case of 54 institutions, the variation in ranks is between 1 to 5 if scores of Perception/ Reputation are taken into consideration or not, while in the case of 21 universities the variation is in the range of 6 to 10 .

3. For 5 universities, the variation in the ranking has been observed to be in the range of 11 to 15 positions. (It is to be noted that in the NIRF Ranking, perception score is only 10\% which also includes 3\% for accreditation).

Table I summarizes the Results.

\section{Concluding Remarks}


The focus in this Paper is on the determination and use of the Perception Score in Global and National Rankings of Universities. It is argued that Perception is entirely subjective and comes in the way of providing a level playing field for all institutions. THE and QS accord about half of the overall scores to Perception and claim it as their principal feature, with built-in safeguards; but it has several pitfalls. For institutions at the top, it appears to have minimal influence, whereas for those in the lower half of the lists, it makes a big difference. The NIRF attaches a small (7\%) score to Perception for determining which considerable effort is required, and it does not seem to make much difference to the Rankings.

The emergence and rising prominence of global rankings is inevitable. It highlights the fact that in a competitive global economy, national pre-eminence is no longer sufficient. The popularity of rankings is largely related to their simplicity - but this is also the main source of criticism due to some indicators such as Perception which is not quantifiable and gives wrong notion to the stakeholders about the performance of the institution.

\section{Table I}

\begin{tabular}{|c|c|c|c|c|c|c|c|c|c|c|c|c|c|c|c|c|c|c|c|c|c|c|}
\hline \multirow[t]{2}{*}{ Ranking } & \multirow{2}{*}{$\begin{array}{c}\text { No } \\
\text { Change }\end{array}$} & \multicolumn{3}{|c|}{$1-5$} & \multicolumn{3}{|c|}{$6-10$} & \multicolumn{3}{|c|}{$11-20$} & \multicolumn{3}{|c|}{$21-30$} & \multicolumn{3}{|c|}{$31-40$} & \multicolumn{3}{|c|}{$41-50$} & \multicolumn{3}{|c|}{ 51-above } \\
\hline & & + & - & Total & + & - & Total & + & - & Total & + & - & Total & + & - & Total & + & - & Total & + & - & Total \\
\hline Times & 33 & 36 & 20 & 56 & 2 & 8 & 10 & & 1 & 1 & & & & & & & & & & & & \\
\hline NIRF & 22 & 24 & 30 & 54 & 10 & 11 & 21 & 2 & 1 & 3 & & & & & & & & & & & & \\
\hline QS-Asia & 2 & 13 & 17 & 30 & 6 & 8 & 14 & 16 & 9 & 25 & 4 & 9 & 13 & 3 & 5 & 8 & 4 & 3 & 7 & 1 & & 1 \\
\hline QS-World & 4 & 12 & 12 & 24 & 4 & 9 & 13 & 10 & 17 & 27 & 3 & 8 & 11 & 3 & 8 & 11 & 3 & 1 & 4 & 6 & & 6 \\
\hline
\end{tabular}

\begin{tabular}{|c|c|c|c|c|}
\hline Ranking & No Change in Rank & Increased in Rank & Decreased in Rank & Total \\
\hline Times & 33 & 38 & 29 & 100 \\
\hline NIRF & 22 & 36 & 42 & 100 \\
\hline QS-Asia & 2 & 47 & 51 & 100 \\
\hline QS-World & 4 & 41 & 55 & 100 \\
\hline
\end{tabular}

\section{Annexure I}

Methodology for determining Perception Score in QS Rankings

"Once the responses have all been processed, "the fun really begins" and it works as follows for each of our five subject areas:

1. Devise weightings based on the regions with which respondents consider themselves familiar - weightings are (now) based only on completed responses for the given question. This is slightly complicated by the fact that respondents are able to relate to more than one region.

2. Derive a weighted count of international respondents in favour of each institution, ensuring that any self-references are excluded.

3. Derive a count of domestic respondents in favour of each institution, adjusted against the number of institutions from that country with a certain level of international nominations and the total response from that country, ensuring any self-references are excluded.

4. Apply a straight scaling to each of these to achieve a score out of 100.

5. Combine the two scores with a weighting of $85 \%$ for international, and $15 \%$ for domestic - these numbers were based on analysis of responses received before we separated the domestic and international responses three years ago, but a low weighting for domestic also reflects the fact that this is a world university ranking. We use 50:50 for the employer review.

6. Square root the result - we do this to draw in the outliers but to a lesser degree than other methods might achieve - our intention is that excellence in one of our five areas should have an influence, but not too much of influence.

7. Scale the rooted score to present a score out of 100 for the given faculty area.

8. Combine the five totals with equal weighting to result in a final score which will then be standardized relative to the sample of institutions being used in any given context". 
Volume 2 Issue 2 February 2022

(C) All rights are reserved by Madhu B K., et al. 